\title{
See red? Turn pale? Unveiling Emotions through Cardiovascular and Hemodynamic Changes
}

\author{
Pedro Montoya ${ }^{1}$, J. Javier Campos ${ }^{2}$, and Rainer Schandry ${ }^{3}$ \\ ${ }^{1}$ University of the Balearic Islands, \\ ${ }^{2}$ Complutense Universidad of Madrid, \\ ${ }^{3}$ University of Munich
}

\begin{abstract}
Cardiodynamic and hemodynamic reactions to emotion-eliciting film sequences were investigated. Thirty-two healthy subjects (12 women, 20 men) were randomly assigned to one of two groups. In the first group, anger was induced using selected scenes of the film "Ragtime." In the second group, scenes of the film "The Shining" were chosen to elicit fear. A documentary film was used as a baseline stimulus in both groups. EKG, impedance cardiography, and blood pressure were continuously monitored. The two emotional conditions elicited significant differential changes in subjective ratings and cardiovascular indices. Fear was associated with decreased cardiac output, increased total peripheral resistance, and a reduction in stroke volume and myocardial contractility. Anger was associated with an increase of cardiac output and small changes in total peripheral resistance. These results support the hypothesis that discrete emotions such as fear and anger elicit differential patterns of physiological responses.
\end{abstract}

Keywords: humans, impedance cardiography, blood pressure, anger, fear, anxiety

\begin{abstract}
Se investigaron las reacciones cardiodinámicas y hemodinámicas asociadas a la visión de secuencias de películas con distinto contenido emocional. Treinta y dos sujetos (12 mujeres y 20 hombres) se asignaron al azar a uno de los dos grupos. En un grupo se indujo la ira utilizando una selección de escenas de la película "Ragtime". En el segundo grupo se escogieron escenas de la película "El Resplandor" para elicitar el estado afectivo relacionado con el miedo. Se utilizó un documental para establecer la línea de base en ambos grupos. Se registró de modo continuo la presión sanguínea, el EKG y la cardiografía de impedancia. Las dos condiciones emocionales relacionadas con el miedo o la ira mostraron cambios diferencialmente significativos en la valoración introspectiva realizada por los sujetos y en los índices cardiovasculares. El miedo se asociaba con un descenso de la salida cardiaca, un incremento de la resistencia periférica total y una reducción del volumen sanguíneo y de la contractilidad miocárdica. La ira estaba asociada con un incremento de la salida cardiaca y cambios reducidos en la resistencia periférica. Estos resultados apoyan la hipótesis de que las emociones discretas de miedo e ira elicitan patrones diferenciados de respuestas psicofisiológicas.

Palabras clave: humanos, cardiografía de impedancia, presión sanguínea, ira, miedo, ansiedad
\end{abstract}

This research was supported by the Deutsche Forschungsgemeinschaft (grant Scha 308/4). Manuscript preparation was possible by grants from the Spanish Secretaría de Estado de Universidades to PM (grant PR2003-0255) and JJC (grant PR2003-0071).

The authors acknowledge the assistance of Mrs. I. Huttinger and Mrs. C. Rothmeier in data acquisition.

Address correspondence to: Dr. Pedro Montoya, Department of Psychology, University of the Balearic Islands, 07071 Palma de Mallorca, Spain. E-mail: pedro.montoya@uib.es. Phone +34 971 172646. Mobile phone +34 656913926 . Fax: +34 971172309 
It is commonly accepted that emotions consist of physiological changes, subjective experience, and overt behavior (Lang, 1979). Although emotional states and overt affective behaviors seem to serve a function (e.g., to prepare the individual for an avoidance behavior), a question arises concerning the relevance of physiological changes to the experience of emotion (Miller \& Kozak, 1993). Some researchers argued that these changes reflect an unspecific arousal which would accompany emotional settings (Cannon, 1927). Others claimed that physiological changes help to discriminate different emotional states (Ekman, Levenson, \& Friesen, 1983; Levenson, 1992).

There is considerable evidence supporting the notion that different emotions are accompanied by specific patterns of physiological arousal (Ax, 1953; Cacioppo Klein, Bernston, \& Hatfield, 1993; Ekman et al., 1983; Harrison et al., 2000; Lang, Bradley, \& Cuthbert, 1998; Neumann \& Waldstein, 2001; Prkachin, Williams-Avery, Zwaal, \& Mills, 1999; Roberts \& Weerts 1982; Schwartz, Weinberger, \& Singer, 1981; Sinha, Lovallo, \& Parsons, 1992). Most of these investigations have focused on changes in cardiovascular activity, and have identified heart rate and blood pressure as the best discriminators. There are, however, few studies concerning the patterns of cardiovascular activity underlying these differential blood pressure and cardiac changes. Access to the relevant cardiovascular activity changes has been facilitated by noninvasive blood-pressure monitor systems, and the possibility of recording cardiac activity with skin electrodes (Papillo \& Shapiro, 1990). Impedance cardiography is a noninvasive method of monitoring cardiac output and systolic time intervals (Sherwood et al., 1990).

Most research employing impedance cardiography, which provides noninvasive and affordable measurements of the cardiovascular response, has focused on the study of exercise physiology (Bogaard et al., 1997; Boutcher \& Stocker, 1999; Richard et al., 2001; Takahashi, Okada, Sayito, Hayano, \& Miyamoto, 2000) or has involved detailed examination of the effects of mental stress on the cardiovascular system (Allen, Matthews, \& Sherman, 1997; Herd, 1991; Ijzerman et al., 2003). Although impedance cardiography might contribute to a better physiological differentiation of emotions, only a few studies have used it for this purpose (Harrison et al., 2000; Neumann et al., 2001; Sinha et al., 1992; Wittling, Block, Schweiger, \& Genzel, 1998). Nonetheless, no clear conclusions have been reached regarding cardiovascular activity during the experience of fear and anger. Sinha et al. (1992) investigated cardiodynamic responses to six imagined emotion conditions (joy, sadness, physical action, fear, anger, and neutral) using impedance cardiography. Physiological responses to aversive emotion scripts (including fear and anger) were, in comparison with neutral and positive emotions, characterized by greater increases in heart rate, systolic blood pressure, and cardiac output, accompanied by greater decreases in stroke volume, left ventricular ejection time (LVET), pre-ejection time (PEP), and peripheral vascular resistance. In comparison to fear imagery, anger was characterized by lower cardiac output and reduced peripheral resistance. Wittling et al. (1998) examined cardiovascular responses to a neutral and an arousing film, and found significant changes on myocardial contractility, cardiac output, PEP, and LVET. Harrison et al. (2000) compared cardiovascular reactions to humorous, exciting, and didactic film presentations. A 10-min extract, showing a "penalty kick" during the 1998 soccer World Cup Final between Argentina and England, was presented as exciting film to keen supporters of the England soccer team. Compared to baseline, the exciting film provoked the highest increases in systolic blood pressure, heart rate, and cardiac output, and shortened PEP. Neumann et al. (2001) examined cardiovascular reactivity during the recall of recent emotional experiences of sadness, anger, joy, and relaxation. All emotional tasks elicited significant increases in heart rate, blood pressure, and total peripheral resistance, and decreases in stroke volume without changes in cardiac output. In comparison with sadness, anger was characterized by minimal changes in PEP and lower enhancement of peripheral resistance.

Elicitation of emotional states in the laboratory can be accomplished by several techniques. One widely used technique is presentation of film material (Palomba, Sarlo, Angrilli, Mini, \& Stegagno, 2000; Palomba \& Stegagno, 1993; Davis, Hull, Young, \& Warren, 1987). There are at least two arguments in favor of the use of movies to investigate cardiovascular reactions to emotion. First, the experimental situation seems better controlled with movies than with imagery scripts. It is known that the effectiveness of imagery scripts in inducing psychophysiological changes is mediated by subjects' ability to vividly imagine the script (Janke \& Debus, 1978). Second, because ensemble averaging of multiple cardiac cycles is recommended for impedance cardiographic measurements (Sherwood et al., 1990; Sherwood \& Turner, 1992), the use of longer-lasting stimuli such as emotional movies allows the experimenter to collect data for a sufficiently long period of time.

The goal of the present experiment was to investigate cardiac differentiation between anger and fear using movies as emotion-eliciting stimuli. This kind of emotion induction allowed us to assess subjects' cardiovascular reactions over an extended time period using impedance cardiography and continuous monitoring of blood pressure, and, thus, to assess and compare blood pressure and heart rate changes during anger and fear.

\section{Method}

\section{Participants}

Thirty-two healthy volunteers (12 women, 20 men) aged 19 to 40 years $(M=26$ years, $S D=4.3)$ were assigned randomly to the fear condition ( $n=16$; 4 women) or the anger condition ( $n=16$; 8 women) groups. 


\section{Stimuli}

Three movies commercially available on videotapes were used in the present experiment. The first tape was the original version of the 5-minute documentary film "The Magic Drop" (directed by Petra Thorbrietz, Germany 1990). The two other tapes consisted of selected sequences from "The Shining" (USA, 1980, directed by Stanley Kubrick) and "Ragtime" (USA, 1981, directed by Milos Forman). "The Shining" dealt with the story of a winter caretaker who was living with his wife and son in an empty hotel, and of his psychological disintegration caused by some strange events. The film "Ragtime" concentrated on the story of an Afro-American ragtime pianist, his troubles with a racist fireman, and his eventual demise as a vengeful radical. Selected scenes from both films were chosen which maintained the thematic structure of the original movies. This resulted in clips lasting 15 minutes.

\section{Self-report measures}

Two questionnaires were administered in each group to assess mood state both at the beginning and at the end of the experiment. The first questionnaire was administered to participants in both groups, who were asked to complete the Mood Adjective Check List (Eigenschafftsworterliste, EWL; Janke \& Debus, 1978). This questionnaire requires respondents to indicate by means of a semantic differential which of a wide variety of mood states they are currently experiencing. The internal consistency of the EWL ranges from .70 to .95 . In this experiment, the following scales were used: Activation, Anger, Anxiety, Confusion, Depression, Deactivation, Dreamy, Excitation, Extraversion, Fatigue, Humor, Introversion, Self-Confidence, and Sensitivity.

Each group also received a different emotion-specific questionnaire. Subjects in the fear group were asked to complete the State form of the State-Trait Anxiety Inventory (STAI; (Laux, Glanzmann, Schaffner, \& Spielberger, 1981; Spielberger, Gorsuch, \& Lushene, 1970). Subjects in the anger group were given the State form of the State-Trait Anger Expression Inventory (STAXI; Schwenkmezger, Hodapp, \& Spielberger, 1989). The internal consistency of these questionnaires ranges from .71 to .95 .

\section{Apparatus and physiological recording}

Four adhesive aluminum strip electrodes were attached to the participant's chest following Sherwoods' guidelines (Sherwood et al., 1990) for impedance cardiography. The inner measuring electrodes were placed around the base of the neck and around the thorax at the level of the xiphisternal joint. The outer electrodes were placed about $5 \mathrm{~cm}$ above and below the measuring electrodes. A current of $4 \mathrm{~mA}$ at $100 \mathrm{kHz}$ was passed through the two outer electrodes. The electrocardiogram $(E K G)$ was recorded using two additional electrodes attached near the seventh left rib and the right collar bone. A ground electrode was placed on the forehead. Signals were amplified by a Picker Polygraph. Blood pressure was continuously monitored with an Ohmeda 2400 FINAPRES device, which employs the vascular unloading principle (Wesseling, Settels, \& deWit, 1986) by recording changes in finger pulse volume. The cuff of the FINAPRES was placed around the third finger of the nondominant hand.

All signals were digitized by a 12-bit A/D converter (DT 2811, sampling rate of $50 \mathrm{~Hz}$ per channel) and stored on a PC.

\section{Procedure}

Upon arrival at the laboratory, participants were told that the goal of the experiment was to investigate cardiac reactions while watching movies. After completing the questionnaires, participants were conducted to the experimental room, the electrodes were attached and the cuff for blood pressure recording was set in place. A 24" TV-monitor was placed about 1.5 meters in front of the participant. For all participants, the control film was followed by the emotional movie with a short pause between the films. Participants were asked to sit comfortably and to enjoy the films. Informed consent was obtained form all participants.

\section{Data reduction}

Physiological signals (dZ/dt, $\mathrm{Z}_{0}$ and EKG waveforms) were segmented in 1000-msec epochs starting $200 \mathrm{msec}$ before each EKG R wave. Then, segments were averaged over the 5 minutes of the control film and the 15 minutes of the emotional film. Cardiovascular parameters were calculated using the following definitions:

1. Heart rate (in bpm) was expressed as number of EKG $\mathrm{R}$ waves per minute.

2. Stroke volume (in $\mathrm{ml}$ ) was calculated according to Kubicek's formula (Kubicek, Patterson, \& Witsoe, 1970):

$\mathrm{SV}=$ rho $*\left(\mathrm{~L} / \mathrm{Z}_{0}\right)^{2} *$ LVET $* \mathrm{dZ} / \mathrm{dt}_{\text {max }}$ where $\mathrm{L}$ is the distance (in $\mathrm{cm}$ ) between the recording electrodes measured at the front, $\mathrm{Z}_{0}$ is the baseline impedance (in ohm) between the recording electrodes, LVET is left ventricular ejection time (in msec), and $\mathrm{dZ} / \mathrm{dt}_{\max }$ is the peak value (in ohm $\mathrm{sec}^{-1}$ ) of the impedance waveform, and Rho represents the resistivity of blood (a value of $135 \mathrm{ohm} \mathrm{cm}$ was used).

3. Pre-ejection period (PEP) is the time (in $\mathrm{msec}$ ) between the occurrence of the EKG Q wave and the $\mathrm{dZ} / \mathrm{dt} \mathrm{B}$ wave.

4. Left ventricular ejection time (LVET) is the interval (in msec) between the occurrence of the B wave and the $\mathrm{X}$ point of the $\mathrm{dZ} / \mathrm{dt}$ signal. 
5. Cardiac output (in $1 \mathrm{~min}^{-1}$ )was estimated as the product of heart rate by stroke volume (1/min).

6. Myocardial contractility (Heather index, in ohm sec${ }^{2}$ ) was defined as $\mathrm{dZ} / \mathrm{dt}_{\max }$ divided by the interval between the EKG Q wave and the occurrence of $\mathrm{dZ} / \mathrm{dt}_{\max }$.

7. Systolic and diastolic blood pressures (in $\mathrm{mmHg}$ ) were determined by averaging the maximum and minimum values of each cardiac cycle.

8. Mean arterial pressure (in $\mathrm{mmHg}$ ) was estimated by adding the diastolic blood pressure to one-third of the difference between the systolic and diastolic pressures.

9. Total peripheral resistance (in dynesec $\mathrm{cm}^{-5}$ ) was defined as 80 times the ratio of mean blood pressure to $\mathrm{CO}$ multiplied by 80 .

\section{Results}

\section{Affective reactions}

Presentation of the emotional material yielded a significant change of mood state. In both groups, a significant increase of the applicable State Questionnaire scores (STAI or STAXI) was observed at the end of the experiment. The subjective ratings on State Anxiety in the fear group increased from an average score of 38.7 ( $S D=$ 9.6) to $52.6(S D=12.1), t(15)=4.3, p<.01$. Ratings on State Anger in the anger group changed from $14.0(S D=$ $2.6)$ to $22.0(S D=5.0), t(15)=6.3, p<.001$. Analyses of the scores on the EWL scales further confirmed a specific emotion-related change for each group. Significant increases (before and after watching the films) in all EWL scores were observed in both groups, $F_{\mathrm{S}}(1,15)>7.7, p \mathrm{~s}<.05$, with the exception of "humor" in the fear group, $F(1,15)=3.95$, n.s.. Furthermore, higher scores were found in the EWL subscales Anger, $t(30)=2.7, p<.05)$, Activation, $t(30)=$ $3.4, p<.01$ ), and Dreamy, $t(30)=2.0, p<.05$, for the anger group as compared to the fear group. Higher scores were found in the subscale Introversion, $t(30)=2.1, p<.05$, for the fear group as compared to the anger group.

\section{Cardiovascular and hemodynamic reactions}

To assess group differences in baseline, participants' physiological reactions when watching the neutral film were subjected to one-way analyses of variance with the betweensubjects factor Group (fear vs. anger). No group differences were found for any cardiovascular dependent measures (all $F_{\text {s }}(1,30)<2.0$, n.s. $)$, indicating that both groups of subjects reacted to the neutral film similarly.

Thus, change scores were obtained by subtracting the values of the physiological variables while watching the neutral film from those recorded during the emotional film. Figure 1 shows the change scores of the cardiovascular measures for each group. To test for differences on cardiovascular reactivity between groups, one-way ANOVAs with the between-subjects factor Group were computed. Significant differences between the fear and the anger groups were found for heart rate, $F(1,30)=4.17$, $\mathrm{p}<.05$, cardiac output $F(1,30)=9.78, p<.01$, stroke volume, $F(1,30)=4.56, p<.05$, myocardial contractility, $F(1,30)=4.85, p<.05$, and total peripheral resistance, $F(1,30)=4.41, p<.05$. The anger group, compared to the fear group, reacted with more pronounced increases in heart rate, cardiac output, stroke volume and contractility; but with a significant decrease in total peripheral resistance. No significant differences were found for blood pressure, LVET, and PEP reactions.
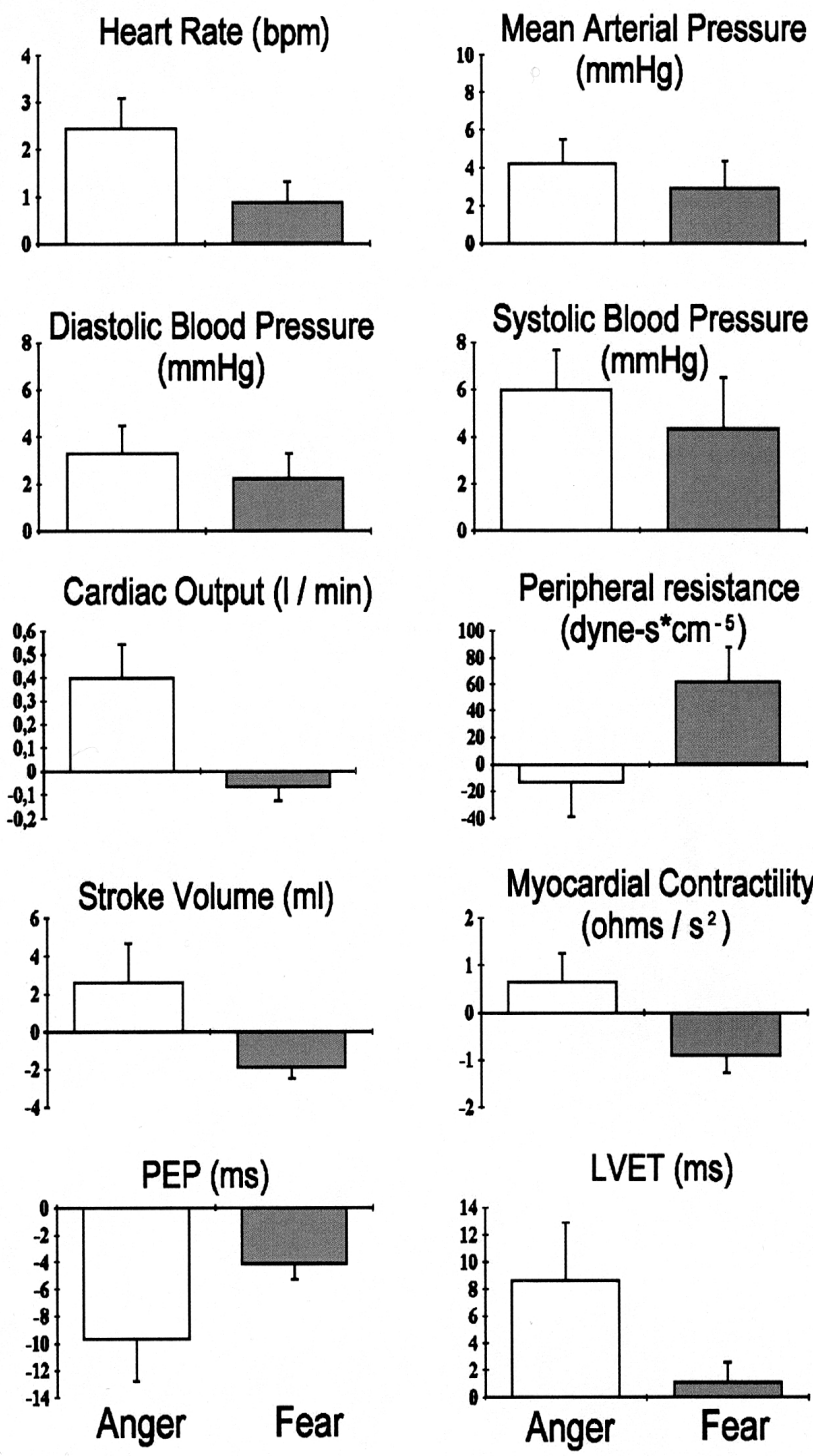

Figure 1. Mean and standard deviation of the cardiodynamic changes from baseline (neutral film) to the emotional film (Fear vs. Anger). 


\section{Discussion}

In the present study, subjective mood ratings and cardiovascular responses to emotional films were assessed. Our data indicate that emotional film sequences elicited significant changes in cardiovascular activity and self-report measures of emotional experience and, more interestingly, that these changes were different for anger and fear.

The analyses of self-report measures of emotional state indicate that the selected film segments were effective in inducing specific mood state changes in each group. As expected, participants watching the fear film rated themselves (as indexed by the State-Trait questionnaires) as more anxious after the film, and participants watching the anger film as more angry (particularly, women were more involved in their expression of anger, rating higher scores). Further support for the effectiveness of emotion induction was provided by the results of the subjective mood questionnaires. Although generally higher scores were observed in both groups in almost all EWL scales after watching the emotional films, significant group differences were found in the EWL scales Anger, Activation, and Dreamy, indicating specific changes of mood state as a consequence of film watching. After the fear-eliciting film, participants experienced less anger, activation, and dreaminess than participants who had watched the angereliciting film. It is interesting to note that the groups did not differ in their scores on other mood states such as Confusion, Depression, Excitation, or Fatigue. These data are in accordance with previous results, indicating that specific changes in participants' self-ratings of emotional experience are associated with watching emotion-inducing films in comparison with neutral films (Brown, Corriveau, \& Monti, 1977; Engel, Frader, Barry, \&, Morrow, 1984; Horowitz, 1976).

Our finding that negative emotional movies elicited changes in physiological activity, in comparison with a neutral documentary film, is also in accordance with previous research. Greater increases in blood pressure (Averill, 1969), heart rate (Palomba \& Stegagno, 1993; Palomba et al., 2000), cortisol level (Brown \& Heninger, 1975; Hubert \& de JongMeyer, 1989, 1991), corrugator activity and skin conductance resistance (Hubert \& de Jong-Meyer, 1991) have been found for negative (fear, anger, sadness) films in comparison with neutral films.

The present experiment has further shown that the elicitation of fear and anger was accompanied by different patterns of cardiovascular activity. Significant differences between participants watching the anger- versus the feareliciting sequences were found in heart rate, stroke volume, myocardial contractility, cardiac output, and total peripheral resistance, whereas no differences were observed in blood pressure, LVET, and PEP. These findings are partially in agreement with other studies examining cardiovascular response patterns elicited by emotion-inducing films
(Harrison et al., 2000; Sinha et al., 1992). In those studies, specific changes in cardiac output and total peripheral resistance were also identified as markers for differential cardiovascular response patterns across negative emotions. Sinha et al. (1992) showed that fear imagery elicited larger peripheral resistance responses than anger imagery. Harrison et al. (2000) found significant enhancements in cardiac output, together with heart rate, systolic blood pressure, and PEP during an exciting film presentation.

It is noteworthy that total peripheral resistance (indexed by the resistance of the vasculature to blood flow) and cardiac output directly affect blood pressure (Miller et al., 1987). Thus, it seems that although anger and fear are both characterized by increased sympathetic activation, cardiovascular variables involved in blood pressure regulation (e.g., cardiac output and peripheral resistance) might be differentially altered during these emotional states. In the present experiment, participants in the anger group reacted with increased cardiac output and myocardial contractility, and with reduced total peripheral resistance; the opposite pattern was observed in the fear group. These results resemble the cardiovascular response patterns observed under stress. It has been shown that active coping during stress (e.g., during a mental arithmetic task) elicits a beta-adrenergic sympathetic pattern with increases in cardiac output, whereas passive coping (e.g., cold pressor test) yields in an alphaadrenergic effect characterized by a pronounced increase in total peripheral resistance (Miller et al., 1987; Turner, 1994). Thus, the hemodynamic reaction pattern observed during fear would correspond to the passive coping responses, whereas the reaction during anger would be more similar to that observed during active coping stress. This is not surprising as stressors are commonly defined as uncontrollable events perceived as physically threatening or psychologically demanding (Lovallo et al., 1985). Cardiovascular responses to stress may serve to mobilize physiological resources to prepare the organism for immediate action and to protect it from damage. Hence, we suggest that certain emotion-related physiological changes may also serve similar purposes. Further research should be done aiming to control the intensity of fear or anger and the validity of film stimuli eliciting the affective states commonly called "fear" or "anger".

In sum, the present data reflect specific patterns of cardiovascular activity in response to fear and anger and those emotions are related with the common pale or red face expressions. Our data add further support to the view that the cardiovascular system distinguishes between emotions (Harrison et al., 2000; Levenson, 1992; Neumann et al., 2001; Sinha et al., 1992), stressing the importance of cardiovascular responses for differentiating discrete emotions such as fear and anger. These specific patterns show that the old controversy started by James-Lange and CannonBard theories (e.g., see Petri, 1991, pp. 57-63) is still unsolved. 


\section{References}

Allen, M.T., Matthews, K.A., \& Sherman, F.S. (1997). Cardiovascular reactivity to stress and left ventricular mass in youth. Hypertension, 30, 82-787.

Averill, J.R. (1969). Autonomic response patterns during sadness and mirth. Psychophysiology, 5, 399-414.

Ax, A.(1953). The physiological differentiation between fear and anger in humans. Psychosomatic Medicine, 15, 433-442.

Bogaard, H.J., Woltjer, H.H., Dekker, B.M., van Keimpema, A.R.J., Postmus, P.E., \& de Vries, P.M.J.M. (1997). Haemodynamic response to exercise in healthy young and elderly subjects. European Journal of Applied Physiology, 75, 435-442.

Boutcher, S.H., \& Stocker, D. (1999). Cardiovascular responses to light isometric and aerobic exercise in 21- and 59-year-old males. European Journal of Applied Physiology, 80, 220-226.

Brown, W., Corriveau, D., \& Monti, P. (1977). Anger arousal by a motion picture: A methodological note. American Journal of Psychiatry, 134, 930-931.

Brown, W., \& Heninger, G. (1975). Cortisol, growth hormone, free fatty acids and experimentally evoked affective arousal. American Journal of Psychiatry, 132, 1172-1176.

Cacioppo, J.T., Klein, D.J., Bernston, G.G., \& Hatfield, E. (1993). The psychophysiology of emotion. In M. Lewis \& J.M. Haviland (Eds.), Handbook of emotions (pp. 119-142). New York: Guilford Press.

Cannon, W.B. (1927). The James-Lange theory of emotions: A critical examination and a alternative theory. American Journal of Psychology, 39, 106-112.

Davis, M.H., Hull, J.G., Young, R.D., \& Warren, G.G. (1987). Emotional reactions to dramatic film stimuli: The influence of cognitive and emotional empathy. Journal of Personality and Social Psychology, 52, 126-133.

Ekman, P., Levenson, R.W., \& Friesen, W.V. (1983). Autonomic nervous system activity distinguishes among emotions. Science, $221,1208-1210$.

Engel, G., Frader, M., Barry, C., \& Morrow, G. (1984). Sadness evoked by a film of grief: An experimental study. International Journal of Psychiatry in Medicine, 14, 1-30.

Folkow, B. (1982). Physiological aspects of primary hypertension. Physiological Review, 62, 347-504.

Harrison, L.K., Carroll, D., Burns, V.E., Corkill, A.R., Harrison, C.M., Ring, C., \& Drayson, M. (2000). Cardiovascular and secretory immunoglobulin A reactions to humorous, exciting, and didactic film presentations. Biological Psychology, 52, 113-126.

Herd, J.A. (1991). Cardiovascular response to stress. Physiological Review, 71, 305-330.

Horowitz, M.W.N. (1976). Stress films, emotion, and cognitive response. Archives of General Psychiatry, 33, 1339-1344.

Hubert, W., \& de Jong-Meyer, R. (1989). Emotional stress and saliva cortisol response. Journal of Clinical Chemistry and Clinical Biochemistry, 27, 235-237.

Hubert, W., \& de Jong-Meyer, R. (1991). Psychophysiological response patterns to positive and negative film stimuli. Biological Psychology, 31, 73-93.
Ijzerman, R.G., Stehouwer, C.D., de Geus, E.J., van Weissenbruch, M.M., Delemarre-van de Waal H.A., \& Boomsma D.I. (2003). Low birth weight is associated with increased sympathetic activity: Dependence on genetic factors. Circulation, 108, 566571.

Janke, W., \& Debus, G. (1978). Die Eigenschaftswörterliste (EWL). Göttingen, Germany: Hogrefe.

Johnson, A.K., \& Anderson, E.A. (1990). Stress and arousal. In J.T. Cacioppo \& L.G. Tassinary (Eds.), Principles of psychophysiology (pp. 216-252). Cambridge: Cambridge University Press.

Kubicek, W.G., Patterson, R.P., \& Witsoe, D.A. (1970). Impedance cardiography as a noninvasive method of monitoring cardiac function and other parameters of the cardiovascular system. Annals of the New York Academy of Sciences, 170, 724-732.

Lang, P.J. (1979). A bio-informational theory of emotional imagery. Psychophysiology 16, 495-512.

Lang. P.J., Bradley, M.M., \& Cuthbert, B.N. (1998). Emotion and motivation: Measuring affective perception. Journal of Clinical Neurophysiology, 15, 397-408.

Laux, L., Glanzmann, P., Schaffner, P., \& Spielberger, C.D. (1981). Das State-Trait-Angstinventar (STAI). Weinheim, Germany: Beltz.

Levenson, R.W. (1992). Autonomic nervous system difference among emotions. Psychological Science, 3, 23-27.

Lovallo, W.R., Wilson, M.F., Pincomb, G.A., Edwards, G.L., Topkinds, P., \& Brackett, D.J. (1985). Activation patterns to aversive stimulation in man: Passive exposure versus effort to control. Psychophysiology, 22, 291-293.

Miller, G.A., \& Kozak, M.J. (1993). Three-systems assessment and the construct of emotion. In N. Birbaumer \& A.Öhman (Eds.), The structure of emotion (pp. 31-47). Toronto: Hogrefe \& Huber.

Miller, G.A., Levin, D.N., Kozak, M.J., Cook, E.W., McLean, A., \& Lang, P.J. (1987). Individual differences in perceptual imagery and psychophysiological response in emotion. Cognition and Emotion, 1, 367-390.

Neumann, S., \& Waldstein, S.R. (2001). Similar patterns of cardiovascular response during emotional activation as a function of affective valence and arousal and gender. Journal of Psychosomatic Research, 50, 245-253.

Palomba, D., Sarlo, M., Angrilli, A., Mini, A., \& Stegagno, L. (2000). Cardiac responses associated with affective processing of unpleasant film stimuli. International Journal of Psychophysiology, 36, 45-57.

Palomba, D., \& Stegagno, L. (1993). Physiology, perceived emotion and memory: Responding to film sequences. In N. Birbaumer \& A.Öhman (Eds.), The structure of emotion (pp. 156-168). Toronto: Hogrefe \& Huber.

Papillo, J.F., \& Shapiro, D. (1990). The cardiovascular system. In J.T. Cacioppo \& L.G. Tassinary (Eds.), Principles of psychophysiology (pp. 456-512). Cambridge: Cambridge University Press.

Petri, H.L. (1991). Motivation: Theory, research and applications. Belmont, CA: Wadsworth. 
Prkachin, K.M., Williams-Avery, R.M., Zwaal, C., \& Mills, D.E. (1999). Cardiovascular changes during induced emotion: An application of Lang's theory of emotional imagery. Journal of Psychosomatic Research, 47, 255-267.

Richard, R., Lonsdorfer-Wolf, E., Charloux, A., Doutreleau, S., Buchheit, M., Oswald-Mammosser, M., Lampert, E., Mettauer, B., Geny, B., \& Lonsdorfer, J. (2001). Noninvasive cardiac output evaluation during a maximal progressive exercise test, using a new impedance cardiograph device. European Journal of Applied Physiology, 85, 202-207.

Roberts, R., \& Weerts, T. (1982). Cardiovascular responding during anger and fear imagery. Psychological Report, 50, 219-230.

Schwartz, G.E., Weinberger, D.A., \& Singer, J.A. (1981). Cardiovascular differentiation of happiness, sadness, anger, and fear following imagery and exercise. Psychosomatic Medicine, 43, 343-364.

Schwenkmezger, P., Hodapp, V., \& Spielberger, C.D. (1989). Das State-Trait Argerausdrucks-Inventar (STAXI). Bern, Switzerland: Huber.

Sherwood, A., Allen, M.T., Fahrenberg, J., Kelsey, R.M., Lovallo, W.R., \& Doornen, U.P. (1990). Methodological guidelines for impedance cardiography. Psychophysiology, 27, 1-22.

Sherwood, A., \& Turner, J.R. (1992). A conceptual and methodological overview of cardiovascular reactivity research. In J.R. Turner, A. Sherwood, \& K.C. Light (Eds.), Individual differences in cardiovascular response to stress (pp. 3-32). New York: Plenum Press.

Sinha, R., Lovallo, W.R., \& Parsons, O.A. (1992). Cardiovascular differentiation of emotions. Psychosomatic Medicine, 54, 422-435.

Spielberger, C.D., Gorsuch, R.L., \& Lushene, R.E. (1970). STAI Manual for the State-Trait Anxiety Inventory. Palo Alto, CA: Consulting Psychologists Press.

Takahashi, T., Okada, A., Sayito, T., Hayano, J., \& Miyamoto, Y. (2000). Difference in human cardiovascular response between upright and supine recovery from upright cycle exercise. European Journal of Applied Physiology, 81, 233-239.

Turner, J.R. (1994). Cardiovascular reactivity and stress. New York: Plenum Press.

Wesseling, K.H., Settels, J.J., \& deWit, B. (1986). The measurement of continuous finger arterial pressure noninvasively in stationary subjects. In T.H. Schmidt, T.M. Dembroski, \& G. Blümchen (Eds.), Biological and psychological factors in cardiovascular disease (pp. 355-375). Berlin: Springer-Verlag.

Wittling, W., Block, A., Schweiger, E., \& Genzel, S. (1998). Hemisphere asymmetry in sympathetic control of the human myocardium. Brain and Cognition, 38, 17-35.

Received: December 16, 2004 Revision received: January 21, 2005 Accepted: February 1, 2005 